\title{
Synergistic Effect of Iodide Ion and 4-Hydroxy Coumarin on the Corrosion Inhibition of Mild Steel in Hydrochloric Acid
}

\author{
Shyamala R. Krishnamurthy and Meenakshi H. N. Parameswaran \\ Department of Chemistry, Avinashilingam Institute for Home Science and Higher Education for Women, Coimbatore, \\ Tamil Nadu 641043, India \\ Correspondence should be addressed to Meenakshi H. N. Parameswaran; meenaparam75@gmail.com
}

Received 21 May 2013; Accepted 10 June 2013

Academic Editors: C. Gervasi and H. Miao

Copyright (C) 2013 S. R. Krishnamurthy and M. H. N. Parameswaran. This is an open access article distributed under the Creative Commons Attribution License, which permits unrestricted use, distribution, and reproduction in any medium, provided the original work is properly cited.

\begin{abstract}
No discussion of the use of inhibitors in acid solution is complete without mentioning the phenomenon of synergism. Synergism also operates in corrosion protection where an enhanced inhibition may be related to interaction between inhibitor compounds. This effect has been observed since the earlier days of inhibitor technology and continues to be a potent tool in the development of acid inhibitors for specialized uses. Hence, in this paper, the corrosion inhibition behavior of mild steel (MS) in $1 \mathrm{M}$ hydrochloric acid in the presence of 4-hydroxy coumarin $(4 \mathrm{HC})$ and potassium iodide (KI) has been investigated using the mass loss method and electrochemical techniques. The inhibitive performance of $4 \mathrm{HC}$ is considerably enhanced by the addition of $1 \times 10^{-3} \mathrm{KI}$. The addition of $\mathrm{KI}$ to different concentrations of $4 \mathrm{HC}$ has intensified its efficiency through considerable reduction in the mass loss, corrosion current density $I_{\text {corr }}$, double layer capacitance $C_{\mathrm{dl}}$, and increase in charge transfer resistance $R_{\mathrm{ct}}$. The calculated synergism parameter " $S$ " is greater than unity, thereby proving the fact that the improvement in inhibition efficiency of $4 \mathrm{HC}$, generated by the addition of KI, is due to synergism.
\end{abstract}

\section{Introduction}

Synergism literally means joint action of different processes in producing an effect greater than the sum of their individual effects. This effect has been observed since the earlier days of inhibitor technology and continues to be a potent tool in the development of acid inhibitors for specialized uses. In fact, the inhibitive nature of most of the extracts of common plants used to combat corrosion of metals is known to be fortified through synergism of many organic constituents present. In modern practice, inhibitors are rarely used in the form of single compounds. A formulation of two or more organic compounds and/or inorganic compounds is usually employed. The synergistic action of anions on the inhibition of mild steel corrosion in acid solution containing organic compound has been reported by several authors [1-4]. In view of this, the enhancement of protection efficiency of the chosen coumarin inhibitor by iodide ions against mild steel corrosion in $1 \mathrm{M}$ hydrochloric acid has been studied.

\section{Experimental Parts}

2.1. Synthesis of 4-Hydroxy Coumarin. The microwave assisted synthesis of 4-hydroxy coumarin (4HC) was carried out in an ordinary domestic microwave oven by the von Pechmann reaction of phenol, malonic acid fused $\mathrm{ZnCl}_{2}$, and a few drops of $\mathrm{POCl}_{3}$ for $60-40$ seconds at $450 \mathrm{~W}$. The mechanism of the reaction is shown in Scheme 1 [5].

2.2. Preparation of the Sample. MS specimens of area $5 \times$ $1 \mathrm{~cm}^{2}$ having composition $\mathrm{C}=0.049 \%, \mathrm{Mn}=0.346 \%, \mathrm{Si}=$ $0.026 \%, \mathrm{P}=0.038 \%, \mathrm{~S}=0.020 \%, \mathrm{Cr}=0.050 \%$, Mo $=0.019 \%$, $\mathrm{Ni}=0.019 \%$, and the reminder Fe were used for the entire study. MS specimens with an exposed area of $1 \mathrm{~cm}^{2}$ were used for polarization and impedance studies. The specimens were degreased, cleaned with fine quality emery sheet, washed with distilled water, and stored in desiccators before they are used for the investigation. 
TABLE 1: \%IE in presence of $10^{-3} \mathrm{M} \mathrm{KI}$ and synergism parameter.

\begin{tabular}{|c|c|c|c|c|c|c|c|c|}
\hline & & $10^{-3} \mathrm{M} \mathrm{KI}$ & 0.001 & 0.003 & 0.005 & 0.007 & 0.009 & 0.01 \\
\hline \multirow{3}{*}{$1 \mathrm{~h}$} & $I_{1}, I_{2}$ & 0.1778 & 0.0500 & 0.1537 & 0.2583 & 0.3718 & 0.4329 & 0.5586 \\
\hline & $I_{1+2}^{\prime}$ & - & 0.3472 & 0.4966 & 0.6200 & 0.6687 & 0.7122 & 0.7920 \\
\hline & $S$ & - & 1.1970 & 1.3820 & 1.6650 & 1.5590 & 1.6200 & 1.7450 \\
\hline \multirow{3}{*}{$3 \mathrm{~h}$} & $I_{1}, I_{2}$ & 0.0915 & 0.0996 & 0.2727 & 0.3402 & 0.4373 & 0.4460 & 0.5678 \\
\hline & $I_{1+2}^{\prime}$ & - & 0.2610 & 0.4537 & 0.4959 & 0.5820 & 0.6474 & 0.7537 \\
\hline & $S$ & - & 1.1070 & 1.2100 & 1.1890 & 1.2230 & 1.4270 & 1.5940 \\
\hline \multirow{3}{*}{$6 \mathrm{~h}$} & $I_{1}, I_{2}$ & 0.2799 & 0.2665 & 0.3949 & 0.4164 & 0.4897 & 0.5742 & 0.6252 \\
\hline & $I_{1+2}^{\prime}$ & - & 0.5339 & 0.5814 & 0.6189 & 0.6699 & 0.7307 & 0.7589 \\
\hline & $S$ & - & 1.1330 & 1.0410 & 1.1030 & 1.1130 & 1.1390 & 1.1200 \\
\hline \multirow{3}{*}{$12 \mathrm{~h}$} & $I_{1}, I_{2}$ & 0.1139 & 0.1483 & 0.3011 & 0.3731 & 0.4592 & 0.4611 & 0.4759 \\
\hline & $I_{1+2}^{\prime}$ & - & 0.1907 & 0.3495 & 0.4346 & 0.4795 & 0.5619 & 0.6764 \\
\hline & $S$ & - & 0.9330 & 0.9520 & 0.9830 & 0.9210 & 1.0900 & 1.4350 \\
\hline
\end{tabular}

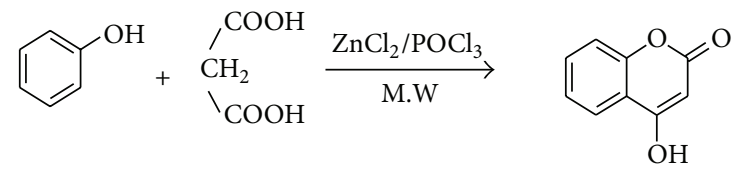

SCHeme 1: Synthesis of 4-hydroxy coumarin.

2.3. Weight Loss Method. MS specimens were accurately weighed and fully immersed in $100 \mathrm{~mL}$ of $1 \mathrm{M} \mathrm{HCl}$ in the absence and presence of the inhibitors, of various concentrations, removed after a particular period of immersion, dipped in sodium bicarbonate solution, (for neutralizing the remaining acid on the specimen), washed, dried, and reweighed. The loss in weight was determined in triplicate and the results were averaged. The experiment was performed for investigating the parameters such as inhibitor concentration $(0.001$ to $0.01 \mathrm{M})$, immersion $(1 \mathrm{~h}, 3 \mathrm{~h}, 6 \mathrm{~h}$, and $12 \mathrm{~h})$, and synergism (presence of $10^{-3} \mathrm{M} \mathrm{KI}$ ). The rates of corrosion and inhibition efficiency were calculated by the following formulae [6]:

Corrosion rate (mpy)

$$
=\frac{534 \times \text { weight loss in } \mathrm{mgs}}{\text { Density } \times \text { Area in square inch } \times \text { Time in hrs }} \text {, }
$$

$\mathrm{IE} \%=($ Corrosion rate without inhibitor

- Corrosion rate with inhibitor)

$\times(\text { Corrosion rate without inhibitor })^{-1} \times 100$.

2.4. Polarization Technique. A frequency response analyzer 1280B (Solartron) and an IBM personal computer were used for the polarization study. The cell for the polarization studies was a glass beaker containing the aerated unstirred test solution with a platinum electrode as the counter electrode, a saturated calomel electrode as the reference electrode, and the mild steel electrode as the working electrode. $100 \mathrm{~mL}$ of $1 \mathrm{M}$ $\mathrm{HCl}$ with and without different concentrations of inhibitors was taken in an electrochemical cell. The polished electrode was then introduced. The electrode was placed at $-1 \mathrm{mV}$ cathodic to its open circuit potential. Thus, the potential was scanned at $-0.1 \mathrm{mV} / \mathrm{sec}$ towards the anodic direction in Tafel extrapolation. Applied potential versus current was plotted and on extrapolation of linear portion to the corrosion potential gives the corrosion current. In anodic and cathodic plots, the slope of the linear portion gave Tafel constants " $b_{a}$ " and " $b_{c}$ " respectively. Inhibition efficiency was calculated by the following formula $[7,8]$ :

$$
\begin{aligned}
& \mathrm{IE} \%=(\text { Corrosion current without inhibitor } \\
&- \text { Corrosion current with inhibitor }) \\
& \times(\text { Corrosion current with inhibitor })^{-1} \times 100 .
\end{aligned}
$$

2.5. AC Impedance Method. The electrochemical impedance measurements were carried out using mild steel in acid medium with and without an inhibitor using the same potentiostat. A plot of real part of impedance $\left(z^{\prime}\right)$ and imaginary part of impedance $\left(z^{\prime \prime}\right)$ was made, and from this, the charge transfer resistance $\left(R_{\mathrm{ct}}\right)$, double layer capacitance $\left(C_{\mathrm{dl}}\right)$, and inhibition efficiency were calculated using ZView software. The inhibitor efficiency was obtained from the electrochemical parameters as below [9-11]

$$
\begin{aligned}
& \% \mathrm{IE}=\frac{\mathrm{Rp}_{(i)}-\mathrm{Rp}}{\mathrm{Rp}_{(i)}} \times 100, \\
& \% \mathrm{IE}=\frac{\operatorname{Rct}_{(i)}-\mathrm{Rct}}{\mathrm{Rct}_{(i)}} \times 100,
\end{aligned}
$$

where Rp and Rct are Polarization resistance and charge transfer resistance in the absence of the inhibitor, respectively, and $\mathrm{Rp}_{(i)}$ and $\mathrm{Rct}_{(i)}$ are Polarization resistance and charge transfer resistance in the presence of the inhibitor, respectively.

\section{Results and Discussion}

3.1. Mass Loss Method. The values of IE for the specific concentrations of $4 \mathrm{HC}$ and in combination with $10^{-3} \mathrm{M}$ KI are given in Table 1. The interesting feature of the investigation is 
TABLE 2: Electrode kinetic parameters for corrosion of mild steel in $1 \mathrm{M} \mathrm{HCl}$ with various concentrations of 4-hydroxy coumarin in the presence and absence of $10^{-3} \mathrm{M}$ KI.

\begin{tabular}{|c|c|c|c|c|c|c|c|}
\hline [Inh] M & [KI] M & $-E_{\text {corr }} \mathrm{mV}$ & $I_{\text {corr }} \mathrm{mA} / \mathrm{cm}^{2}$ & $b_{a} \mathrm{mV} / \mathrm{dec}$ & $b_{c} \mathrm{mV} / \mathrm{dec}$ & $\% \mathrm{IE}$ & $S$ \\
\hline Blank & - & 506 & 11.12 & 206 & 166 & - & - \\
\hline- & $10^{-3}$ & 503 & 8.39 & 199 & 162 & 24.55 & - \\
\hline 0.001 & - & 509 & 10.04 & 230 & 180 & 9.73 & 1.126 \\
\hline- & $10^{-3}$ & 496 & 6.72 & 152 & 130 & 39.52 & \\
\hline 0.007 & - & 483 & 6.54 & 199 & 143 & 41.19 & 1.197 \\
\hline- & $10^{-3}$ & 516 & 4.12 & 149 & 152 & 62.94 & \\
\hline 0.009 & - & 492 & 6.40 & 180 & 143 & 43.17 & 1.167 \\
\hline- & $10^{-3}$ & 496 & 4.08 & 163 & 129 & 63.27 & \\
\hline 0.010 & - & 495 & 4.41 & 174 & 154 & 60.81 & 1.128 \\
\hline- & $10^{-3}$ & 509 & 2.96 & 126 & 111 & 73.39 & \\
\hline
\end{tabular}

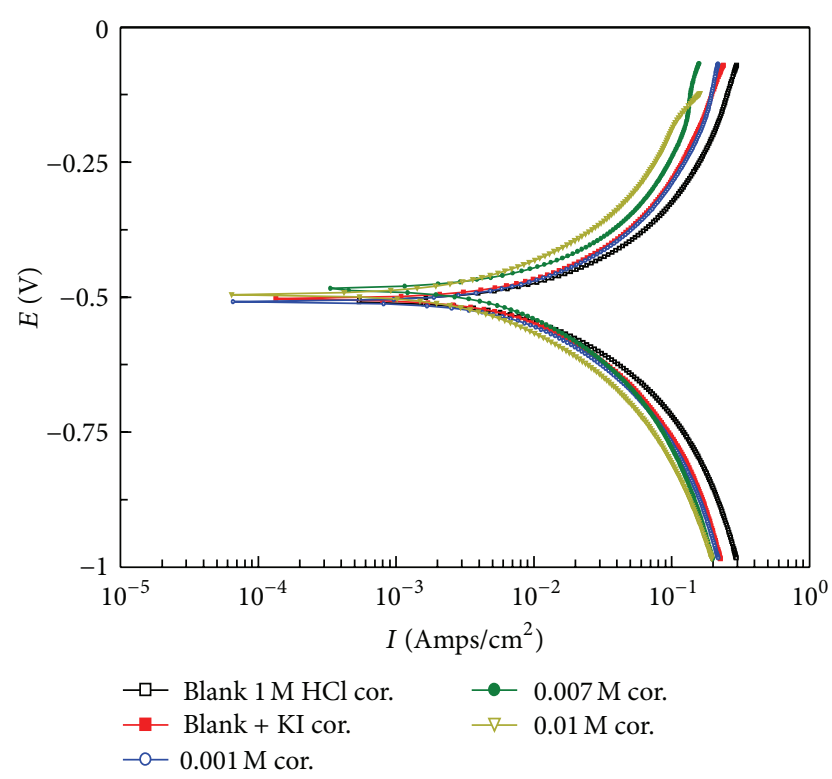

FIGURE 1: Tafel plot for corrosion of mild steel in $1 \mathrm{M} \mathrm{HCl}$ containing different concentrations of 4-hydroxy coumarin.

that the compound gave better inhibitive performance in the presence of $1 \times 10^{-3} \mathrm{M}$ potassium iodide. This enhancement in the IE on the addition of KI occurs due to synergistic effect.

The interaction of inhibitor molecules can be described by the introduction of synergism parameter; $S$ was evaluated using the relationship given by Aramaki and Hackerman and reported elsewhere $[12,13]$

$$
S=\frac{1-I_{1,2}}{1-I_{1+2}} .
$$

$I_{1,2}$ is the calculated inhibition effect supposing additivity (no interaction between the inhibitor compounds exists). $I_{1,2}$ can be expressed as $I_{1,2}=I_{1}+I_{2}-\left(I_{1} I_{2}\right), I_{1}$ is the measured inhibition effect of $1 \times 10^{-3} \mathrm{M} \mathrm{KI}, I_{2}$ is the measured inhibition effect of $4 \mathrm{HC}$, and $I_{(1+2)}$ is the measured inhibition effect for the combination of $4 \mathrm{HC}$ and $1 \times 10^{-3} \mathrm{M}$ KI. The values of "S," the synergism parameter, for different concentrations of $4 \mathrm{HC}$

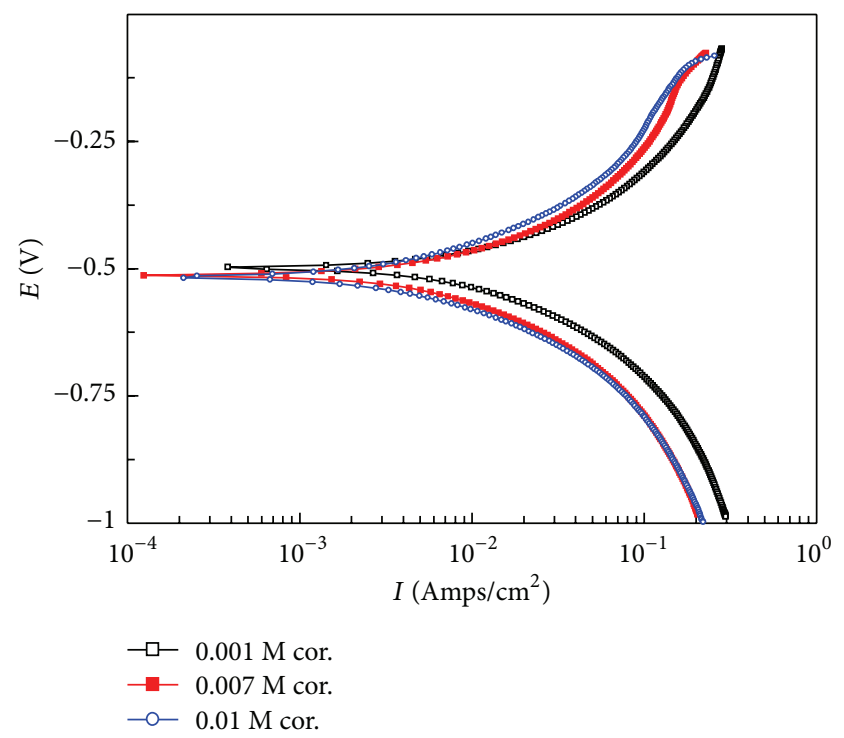

FIGURE 2: Tafel plot for corrosion of mild steel in $1 \mathrm{M} \mathrm{HCl}$ containing different concentrations of 4-hydroxy coumarin in the presence of $10^{-3} \mathrm{KI}$.

in $1 \mathrm{M} \mathrm{HCl}$ in combination with iodide ions are higher than unity suggesting the synergistic effect.

3.2. Polarization Measurements. Figures 1 and 2 represent the anodic and cathodic polarization curves of mild steel in $1 \mathrm{M} \mathrm{HCl}$ devoid of and containing different concentrations of $4 \mathrm{HC}$ and in the presence of $1 \times 10^{-3} \mathrm{M} \mathrm{KI}$. The electrochemical parameters of mild steel corrosion in free and inhibited $1 \mathrm{M}$ $\mathrm{HCl}$ solutions were given in Table 2. It can be seen from the table that as the concentration of the coumarins is increased, there is little change in the corrosion potential. Moreover, the corrosion current $\left(I_{\text {corr }}\right)$ decreases markedly in the presence of the inhibitor, and the magnitude of such an effect increases with increasing inhibitor concentration. These results showed the inhibitive action of the coumarin to corrosion of mild steel in the acidic medium. Also, it can be seen from the table, that the addition of $1 \times 10^{-3} \mathrm{M}$ KI further reduces the $I_{\text {corr }}$ values exhibiting synergism. 


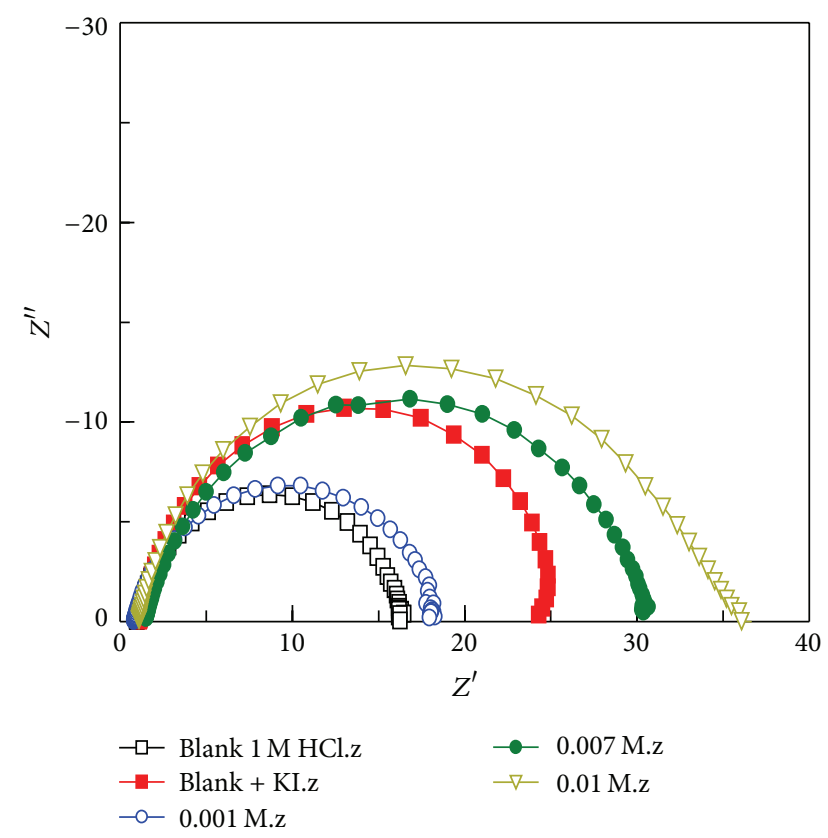

Figure 3: Complex-plane impedance of mild steel in $1 \mathrm{M} \mathrm{HCl}$ with different concentrations of 4-hydroxy coumarin.

The values of inhibition efficiency increase with the increase in coumarin concentrations, reaching the maximum values of $60.81 \%$ at $0.01 \mathrm{M}$. The addition of KI has enhanced the percentage efficiency, which could be attributed to synergistic effect. The presence of synergism has been established by calculating the synergism parameter " $S$ " which is recorded in Table 2. Almost all values are greater than unity, thereby proving the fact that the improvement in inhibition efficiency of $4 \mathrm{HC}$ generated by the addition of $\mathrm{KI}$ is due to synergism.

3.3. Electrochemical Impedance Spectroscopy. Figure 3 represents the Nyquist plot obtained for MS in $1 \mathrm{M} \mathrm{HCl}$ in absence and presence of various concentrations of the inhibitor. Impedance responses of acid solution containing various concentrations of the inhibitor in combination with $1 \times$ $10^{-3} \mathrm{M}$ KI solution are depicted in Figure 4.

The inhibition efficiency was calculated from $C_{\mathrm{dl}}$ values applying the following formula:

$$
\% \mathrm{IE}=1-\left[\frac{C_{\mathrm{dl}(i)}}{C_{\mathrm{dl}}}\right] \times 100,
$$

where $C_{\mathrm{dl}(i)}$ is the double layer capacitance value in the presence of the inhibitor and $C_{\mathrm{dl}}$ is the double layer capacitance value in the absence of the inhibitor.

The calculated inhibition efficiencies from the values of $C_{\mathrm{dl}}$ obtained from the impedance spectra was given in Table 3 . The protecting capacity of $4 \mathrm{HC}$ was found to be increasing with the increase in its concentration. Due to synergism, the addition of KI has caused an enhancement in the protecting ability.

In order to correlate impedance and polarization methods, $I_{\text {corr }}$ values were obtained from the Nyquist plots for

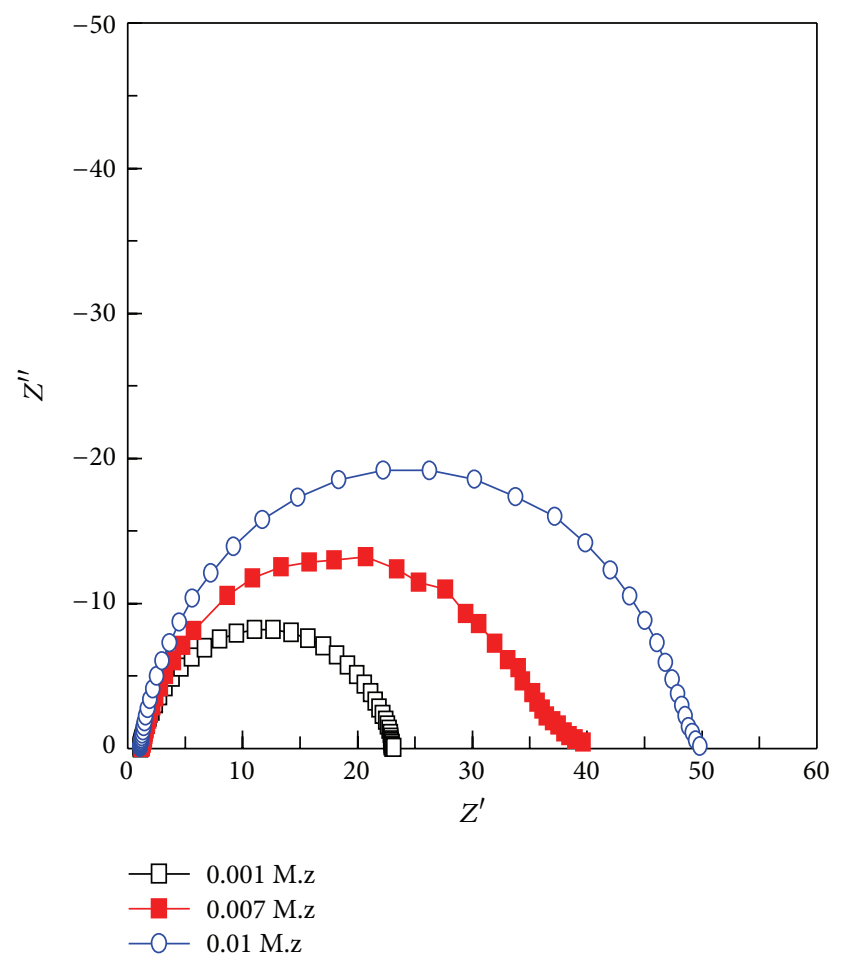

FIgURE 4: Complex-plane impedance of mild steel in $1 \mathrm{M} \mathrm{HCl}$ with different concentrations of 4-hydroxy coumarin in the presence of $10^{-3} \mathrm{M}$ KI.

different concentration of the inhibitor in the absence and presence of $10^{-3} \mathrm{M}$ KI using the Stern-Geary equation [14]:

$$
I_{\text {corr }}=\frac{b_{a} \times b_{c}}{2.3\left(b_{a}+b_{c}\right) R_{\mathrm{ct}}} .
$$

The obtained $I_{\text {corr }}$ and \%IE values with different concentrations of $4 \mathrm{HC}$ in the absence and presence of $\mathrm{KI}$ are given in Table 4 .

The enhanced inhibition efficiency can be explained as due to joint adsorption of iodide ions and inhibitor cations or molecules. When irreversible chemisorption of iodide ions takes place and stable metal-iodide covalent bonds are formed, the iodide ions enter the metallic part of the double layer and the charge of the metal surface, which in turn attracts the positively charged inhibitor cations rendering the adsorption more effective.

Synergism can also happen according to a molecular mechanism. The coumarin cations created as a result of protonation exist only in the solution. On entering the double layer, they become discharged. The molecules produced are adsorbed at the expense of the unpaired electrons of the heteroatom.

\section{Conclusions}

(1) The inhibition efficiency of the inhibitor increased with the increase in its concentration at all immersion times. 
TABLE 3: Impedance parameters for corrosion of mild steel in $1 \mathrm{M} \mathrm{HCl}$ for different concentration of 4-hydroxy coumarin in the presence and absence of $10^{-3} \mathrm{M} \mathrm{KI}$.

\begin{tabular}{|c|c|c|c|c|c|}
\hline [Inh] M & [KI] M & $R_{\mathrm{ct}} \Omega \mathrm{cm}^{2}$ & $\% \mathrm{IE}$ & $C_{\mathrm{dl}} \mu \mathrm{F} / \mathrm{cm}^{2}$ & $\%$ IE \\
\hline Blank & - & 15.65 & - & 425 & - \\
\hline- & $10^{-3}$ & 22.00 & 28.86 & 328 & 22.82 \\
\hline 0.001 & - & 18.03 & 13.20 & 385 & 9.41 \\
\hline - & $10^{-3}$ & 23.04 & 32.07 & 344 & 19.06 \\
\hline 0.003 & - & 19.71 & 20.60 & 376 & 11.53 \\
\hline - & $10^{-3}$ & 23.96 & 34.68 & 318 & 25.18 \\
\hline 0.007 & - & 30.12 & 48.04 & 280 & 34.12 \\
\hline - & $10^{-3}$ & 41.94 & 62.68 & 124 & 70.82 \\
\hline 0.009 & - & 31.44 & 50.22 & 278 & 34.59 \\
\hline - & $10^{-3}$ & 44.31 & 64.68 & 121 & 71.53 \\
\hline 0.010 & - & 37.48 & 58.24 & 149 & 64.94 \\
\hline- & $10^{-3}$ & 51.58 & 69.60 & 111 & 73.88 \\
\hline
\end{tabular}

TABLE 4: Values of $I_{\text {corr }}$ and \%IE for corrosion of mild steel in $1 \mathrm{M}$ $\mathrm{HCl}$ with different concentrations of 4-hydroxy coumarin in absence and presence of $10^{-3} \mathrm{M}$ KI obtained by Stern-Geary equation.

\begin{tabular}{lccc}
\hline$[\mathrm{Inh}] \mathrm{M}$ & {$[\mathrm{KI}] \mathrm{M}$} & $I_{\text {corr }} \mathrm{mA} / \mathrm{cm}^{2}$ & $\% \mathrm{IE}$ \\
\hline Blank & - & 2.55 & - \\
- & $10^{-3}$ & 1.76 & 30.98 \\
0.001 & - & 2.43 & 4.71 \\
- & $10^{-3}$ & 1.01 & 60.39 \\
0.007 & - & 1.20 & 52.94 \\
- & $10^{-3}$ & 0.78 & 69.41 \\
0.009 & - & 1.15 & 54.90 \\
- & $10^{-3}$ & 0.71 & 72.16 \\
0.010 & - & 0.95 & 62.75 \\
- & $10^{-3}$ & 0.50 & 80.39 \\
\hline
\end{tabular}

(2) The presence of $10^{-3} \mathrm{M}$ KI boosted the inhibitive efficiency of the coumarin.

(3) The synergism parameter $S$ obtained by the Aramaki and Hackerman equation was found to be greater than unity. This suggests that the enhanced inhibition efficiency caused by the addition of iodide ion is due only to synergistic effect.

(4) The concentration dependence of the inhibition efficiency calculated from electrochemical studies has the same trend as that obtained from weight loss measurements.

(5) 4-Hydroxy coumarin covers both the anodic and cathodic regions through general adsorption. The adsorption occurs through the activated nonbonded electrons on the lactone oxygen, and the $\pi$ electrons of the aromatic rings can adsorb onto the metal surface. Further, the $-\mathrm{OH}$ group at the 4th position shifts the electron flow towards the pyranone ring due to $+\mathrm{M}$ effect. Also, the oxonium ion formed in the acidic solution can be adsorbed on the metal surface through columbic interaction.

\section{Acknowledgment}

The authors would like to thank the authorities of the Avinashilingam Institute for Home Science and Higher Education for Women for providing necessary facilities to carry out this study.

\section{References}

[1] K. S. Sudhish, K. S. Ashish, C. M. Lutendo, M. K. Mwadham, and E. E. Eno, "Inhibitive effect of azorubine dye on the corrosion of mild steel in hydrochloric acid medium and synergistic iodide additive," International Journal of Electrochemical Science, vol. 7, pp. 5057-5068, 2012.

[2] M. Ajmal, A. S. Mideen, and M. A. Quraishi, "2-hydrazino-6methyl-benzothiazole as an effective inhibitor for the corrosion of mild steel in acidic solutions," Corrosion Science, vol. 36, no. 1, pp. 79-84, 1994.

[3] A. Y. Musa, A. B. Mohamad, A. A. H. Kadhum, M. S. Takriff, and L. T. Tien, "Synergistic effect of potassium iodide with phthalazone on the corrosion inhibition of mild steel in $1.0 \mathrm{M}$ HCl," Corrosion Science, vol. 53, no. 11, pp. 3672-3677, 2011.

[4] E. E. Ebenso, A. Hailemichael, S. A. Umoren, and I. B. Obot, "Inhibition of mild steel corrosion in sulphuric acid using Alizarin yellow GG dye and synergistic iodide additive," International Journal of Electrochemical Science, vol. 3, pp. 13251339, 2008.

[5] V. K. Ahluwalia and R. Aggarwal, Comprehensive Practical Organic Chemistry, Preparation and Quantitative Analysis, Universities Press, Hyderabad, India, 2000.

[6] R. Saratha, M. Saranya Devi, H. N. Meenakshi, and R. Shyamala, "Enhanced corrosion resistance of Tecoma stans extract on mild steel in $0.5 \mathrm{M} \mathrm{H}_{2} \mathrm{SO}_{4}$ solution," International Journal of Current Research, vol. 2, pp. 92-96, 2011.

[7] H. Baeza, M. Guzmán, P. Ortega, and L. Vera, "Corrosion inhibition of copper in $0.5 \mathrm{M}$ hydrochloric acid by 1,3,4thiadiazole-2,5-dithiol," Journal of the Chilean Chemical Society, vol. 48, no. 3, pp. 23-26, 2003.

[8] W. A. W. E. Amira, A. A. Rahim, H. Osman, K. Awang, and P. B. Raja, "Corrosion inhibition of mild steel in $1 \mathrm{M} \mathrm{HCl}$ solution by Xylopia ferruginea leaves from different extract and partitions," 
International Journal of Electrochemical Science, vol. 6, no. 7, pp. 2998-3016, 2011.

[9] S. Ambrish, S. Ashish Kumar, and M. A. Quraishi, "Dapsone: a novel corrosion inhibitor for mild steel in acid media," The Open Electrochemistry Journal, vol. 2, pp. 43-51, 2010.

[10] M. Z. A. Rafiquee, S. Khan, N. Saxena, and M. A. Quraishi, "Influence of some thiadiazole derivatives on corrosion inhibition of mild steel in formic and acetic acid media," Portugaliae Electrochimica Acta, vol. 25, pp. 419-434, 2007.

[11] J.-Q. Xue, M. Wu, J.-X. Li, C.-B. Tang, and C.-X. Yin, "Inhibition behavior of a novel acidification inhibitor for steels at high temperature," Materials Science Forum, vol. 686, pp. 574-578, 2011.

[12] S. A. Umoren and E. E. Ebenso, "The synergistic effect of polyacrylamide and iodide ions on the corrosion inhibition of mild steel in $\mathrm{H}_{2} \mathrm{SO}_{4}$," Materials Chemistry and Physics, vol. 106, no. 2-3, pp. 387-393, 2007.

[13] S. A. Umoren, E. E. Ebenso, P. C. Okafor, U. J. Ekpe, and O. Ogbobe, "Effect of halide ions on the corrosion inhibition of aluminium in alkaline medium using polyvinyl alcohol," Journal of Applied Polymer Science, vol. 103, no. 5, pp. 2810-2816, 2007.

[14] L. Larabi, Y. Harek, M. Traisnel, and A. Mansri, "Synergistic influence of poly(4-vinylpyridine) and potassium iodide on inhibition of corrosion of mild steel in $1 \mathrm{M} \mathrm{HCl,"} \mathrm{Journal} \mathrm{of}$ Applied Electrochemistry, vol. 34, no. 8, pp. 833-839, 2004. 

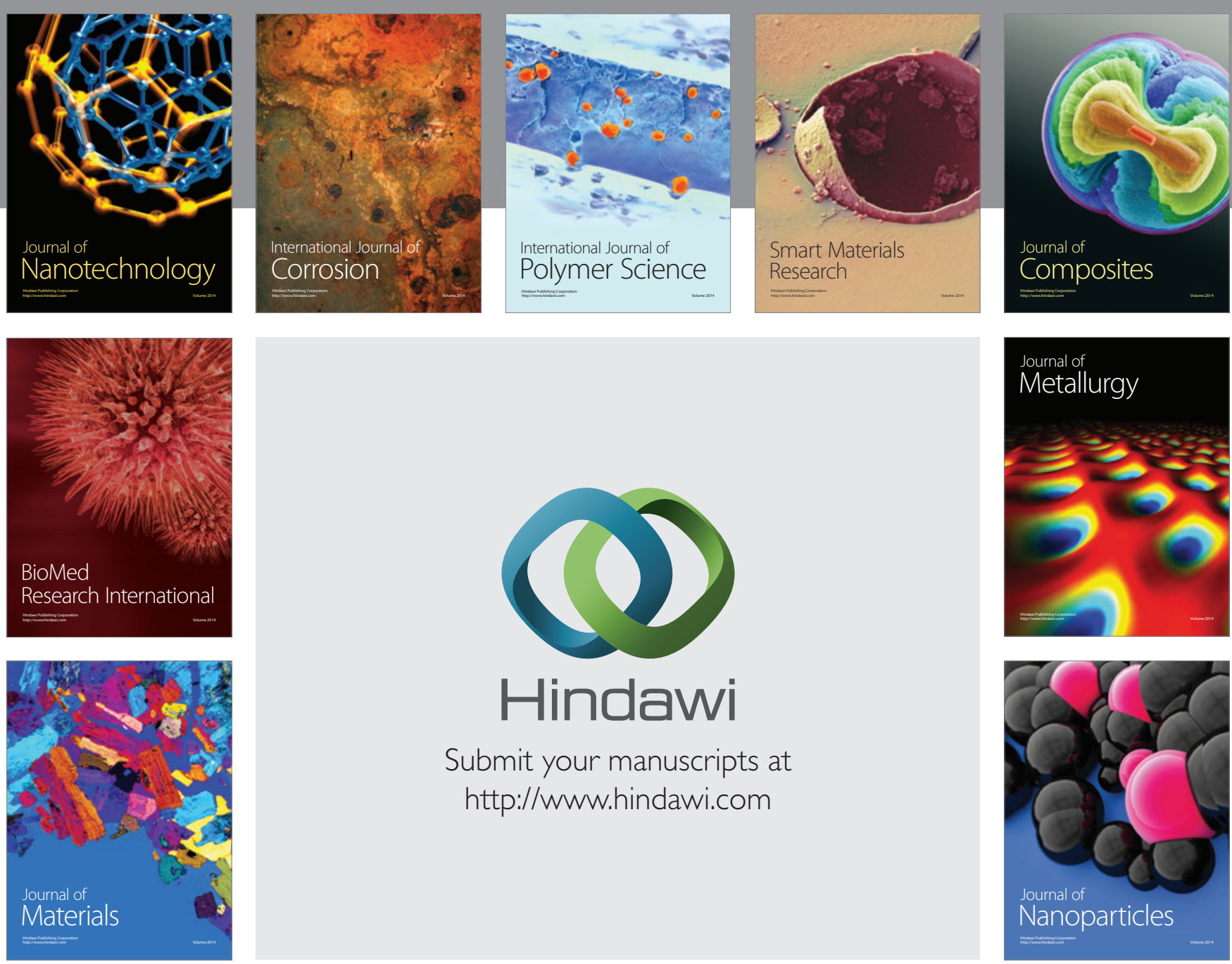

Submit your manuscripts at http://www.hindawi.com
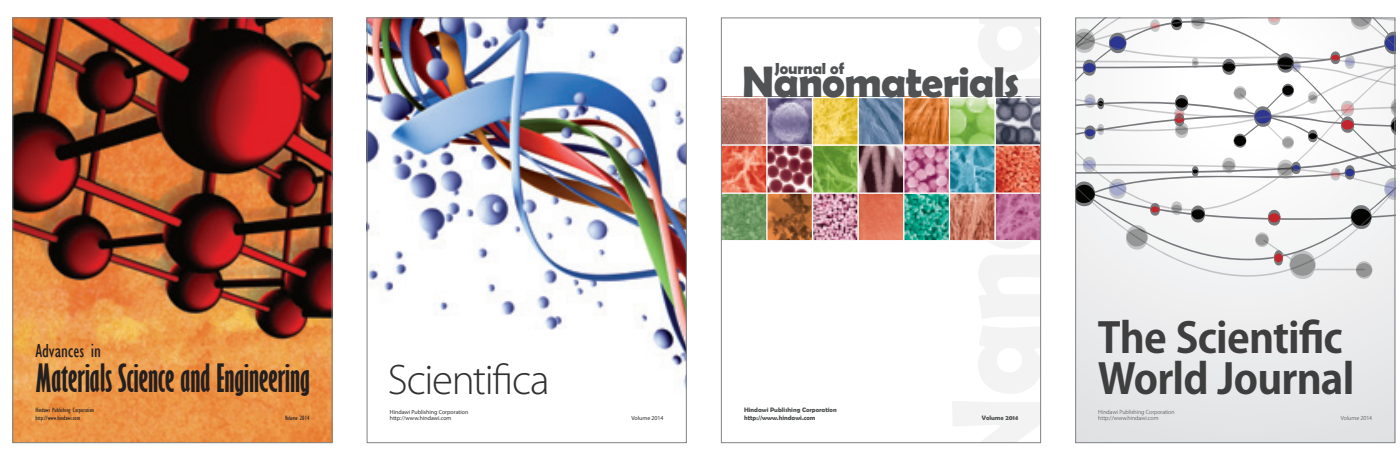

\section{The Scientific World Journal}
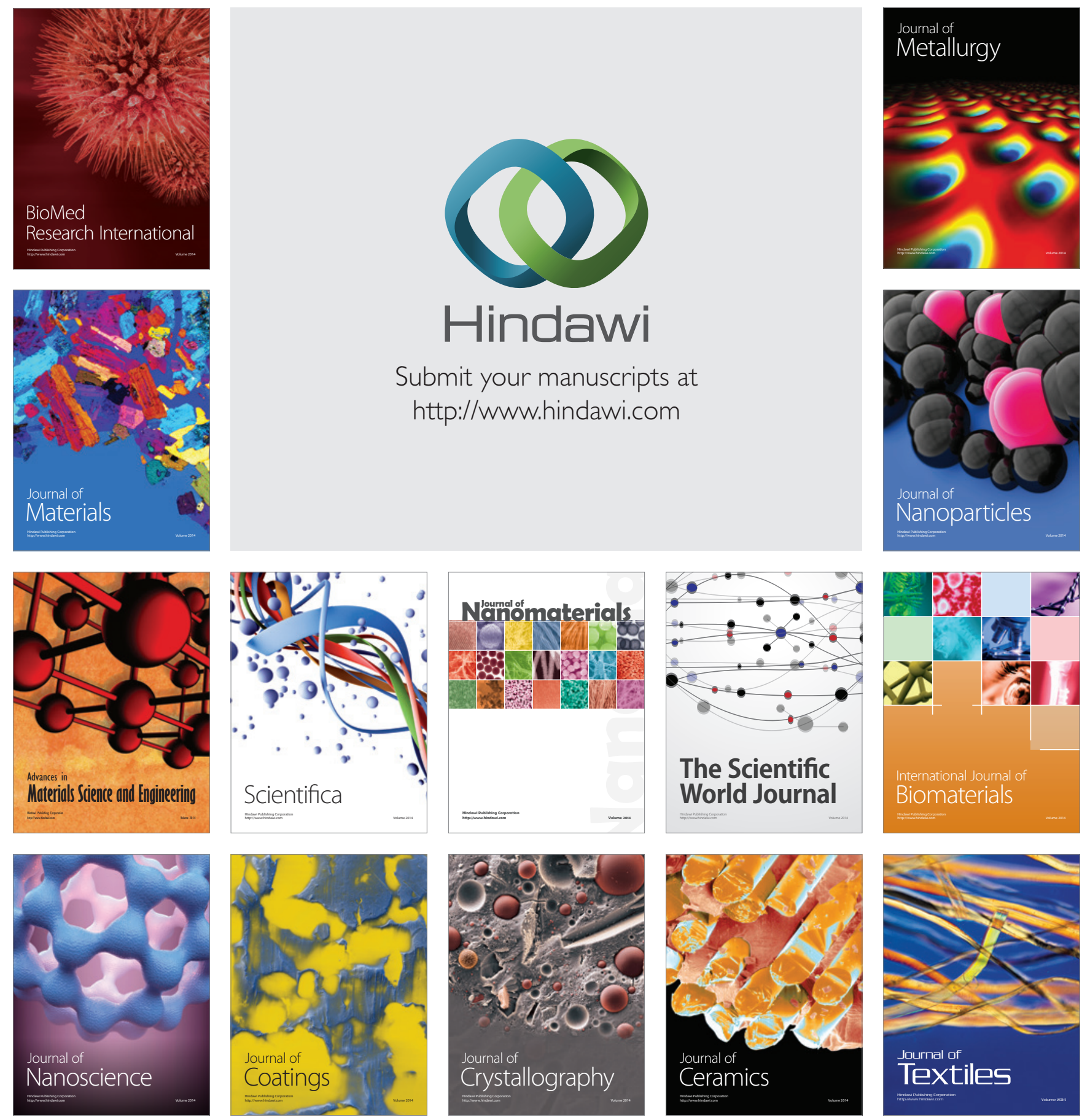